\title{
The influence of the Galápagos Islands on tropical temperatures, currents and the generation of tropical instability waves
}

\author{
C. Eden and A. Timmermann \\ Leibniz-Institut für Meereswissenschaften IFM-GEOMAR, Kiel, Germany
}

Received 23 March 2004; accepted 8 July 2004; published 11 August 2004.

[1] The Galápagos Islands provide a topographic barrier for the Southern Equatorial Current (SEC) and the Equatorial Undercurrent (EUC). An island wake effect can be diagnosed from the difference of an ocean general circulation model simulation which includes the Galápagos Islands and one which ignores their presence. Cold thermocline water upwells on the western side of the islands, and only during boreal winter season these cold waters can linger around the Islands at a depth of about $80 \mathrm{~m}$ and affect the far eastern equatorial Pacific surface waters. This effect is partly offset by the westward transport of cold surface waters by the SEC which creates a wake on the western side of the Islands. It is furthermore shown that changes in horizontal current shear, induced by the presence of the Galápagos Islands modify the generation of tropical instability waves and lead to a basin scale SST anomaly pattern. INDEX TERMS: 4231 Oceanography: General: Equatorial oceanography; 4532 Oceanography: Physical: General circulation; 4255 Oceanography: General: Numerical modeling; 4215 Oceanography: General: Climate and interannual variability (3309); 4279 Oceanography: General: Upwelling and convergences. Citation: Eden, C., and A. Timmermann (2004), The influence of the Galápagos Islands on tropical temperatures, currents and the generation of tropical instability waves, Geophys. Res. Lett., 31, L15308, doi:10.1029/2004GL020060.

\section{Introduction}

[2] The Galápagos Islands are located in a very prominent oceanographic setting: they provide a topographic barrier for the SEC and the EUC. Furthermore, eastward propagating equatorial Kelvin waves, as generated during El Niño and La Niña conditions, have to pass these islands. The topographic features are shown in Figure 1. Theoretical [White, 1971, 1973] and observational studies [Stevenson and Taft, 1971] in the 1970s and 1980s have revealed that the Galápagos Islands have an important influence on the equatorial flow patterns, associated with the EUC and the SEC. The Islands create a wake on the eastern side, which exhibits characteristics both of stationary Rossby wake and a time-dependent Karman wake [White, 1971]. This wake is associated with enhanced upwelling on the western side [Yoshida, 1959] and also enhanced biological productivity [Jimenez, 1981; Arcos, 1981]. Occasionally, the EUC lingers around the Islands as observed by Stevenson and Taft [1971]. Whether this is an expression of seasonality or unstable flow conditions has not been fully resolved.

Copyright 2004 by the American Geophysical Union. 0094-8276/04/2004GL020060
[3] Equatorial waves are also affected by the presence of the topographic barrier as described in the theoretical studies of Rowlands [1982], Yoon [1981], and [LonguetHiggins, 1969] and as observed by Ripa and Hayes [1981]. These topographically induced perturbations to the mean flow and the equatorial waves result in rather complex flow patterns which modify also the generation of baroclinic and barotropic waves near the equator. Our study aims to shed light on the Island wake effects and their impact on wave generation on the equator using an eddy-resolving ocean general circulation model (OGCM) of the tropical Pacific, similar to the work of Brentnall [1999]. Section 2 describes the model setup. The influence of the Galápagos Islands on the mean currents and the cold tongue is discussed in section 3. Section 4 studies the impact of the archipelago on the generation of tropical instability waves. The results are summarized and discussed in section 5 .

\section{Model Setup and Experiments}

[4] We use an OGCM which is part of the FLAME hierarchy of models [Dengg et al., 1999], including versions of different resolution and different parameterizations for subgrid-scale processes. The numerical code is based on a revised version of MOM2 [Pacanowski, 1995]. (The numerical code together with all configurations used in this study can be accessed at http://www.ifm.uni-kiel.de/fb/fb1/ tm/data/pers/ceden/spflame/index.html.) The model version used in the present study is based on a configuration for the tropical Pacific Ocean from $10^{\circ} \mathrm{S}$ to $10^{\circ} \mathrm{N}$ and $124^{\circ} \mathrm{E}$ to $77^{\circ} \mathrm{W}$, with a horizontal resolution of $0.25^{\circ}$ and 42 vertical levels $(10 \mathrm{~m}$ thick at the surface increasing to $250 \mathrm{~m}$ at the bottom). The model is forced using a Haney-type heat flux condition as given by Barnier et al. [1995] and a restoring boundary condition for sea surface salinity, using the Levitus and Boyer [1994] climatology, which serves also as initial condition. Northern and southern margins of the domain are formulated as open boundaries after Stevens [1990] and a buoyancy restoring zone is used for the Indonesian throughflow region. We use lateral biharmonic friction and mixing (viscosity/diffusivity of $1 \times 10^{11}$ and $0.5 \times 10^{11} \mathrm{~m}^{4} / \mathrm{s}$, respectively) and vertical friction and mixing after Gaspar et al. [1990]. During the 10-year-long spinup period the model is forced with climatological monthly windstress given by an ECMWF analysis [Barnier et al., 1995], afterwards using daily wind stress (19902002) taken from the NCEP/NCAR reanalysis data [Kalnay et al., 1996]. We are discussing two experiments with this setup, a standard experiment $(\mathrm{G})$ and an experiment in which the Galápagos Islands are set to a maximal elevation 

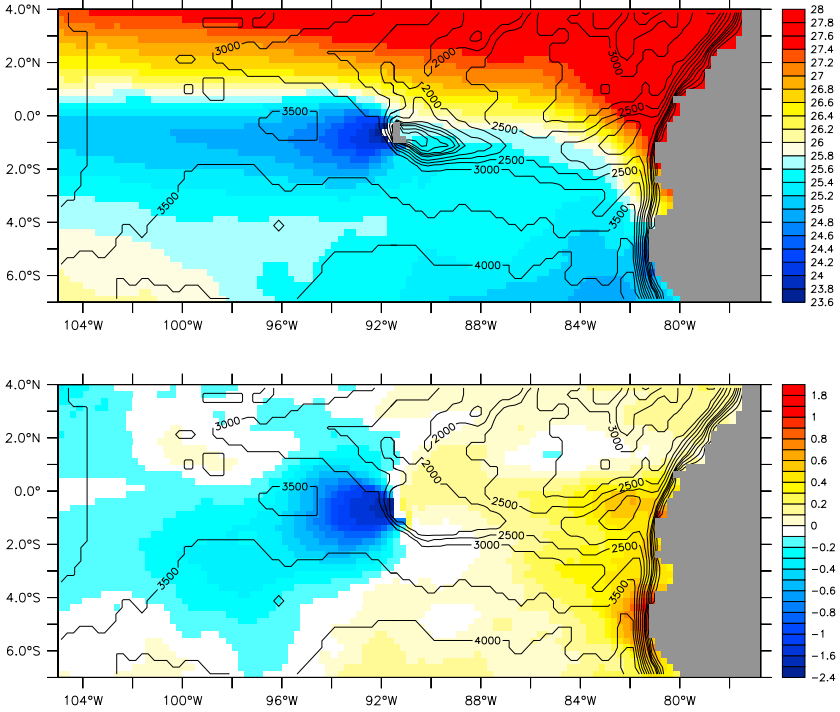

Figure 1. Temperature in $10 \mathrm{~m}$ depth in December (shaded in ${ }^{\circ} \mathrm{C}$ ) in experiment $\mathrm{G}$ (upper panel) and difference in temperature (G-NG) (lower panel) and the topography (contours in $m$ ) in G (upper panel) and NG (lower panel).

of $2000 \mathrm{~m}$ (NG). All results shown are 10-year averages of the 1990's.

\section{Influence on Cold Tongue}

[5] Figure 1 shows the topography in the eastern equatorial Pacific in experiments $\mathrm{G}$ (upper panel) and $\mathrm{NG}$ (lower panel) together with the boreal wintertime near surface temperature in experiment $G$ (upper panel) and the temperature difference between both experiments (lower panel). Note that the difference of experiment $\mathrm{G}$ and $\mathrm{NG}$, i.e., G-NG, shows the effect of the Galápagos Island, as
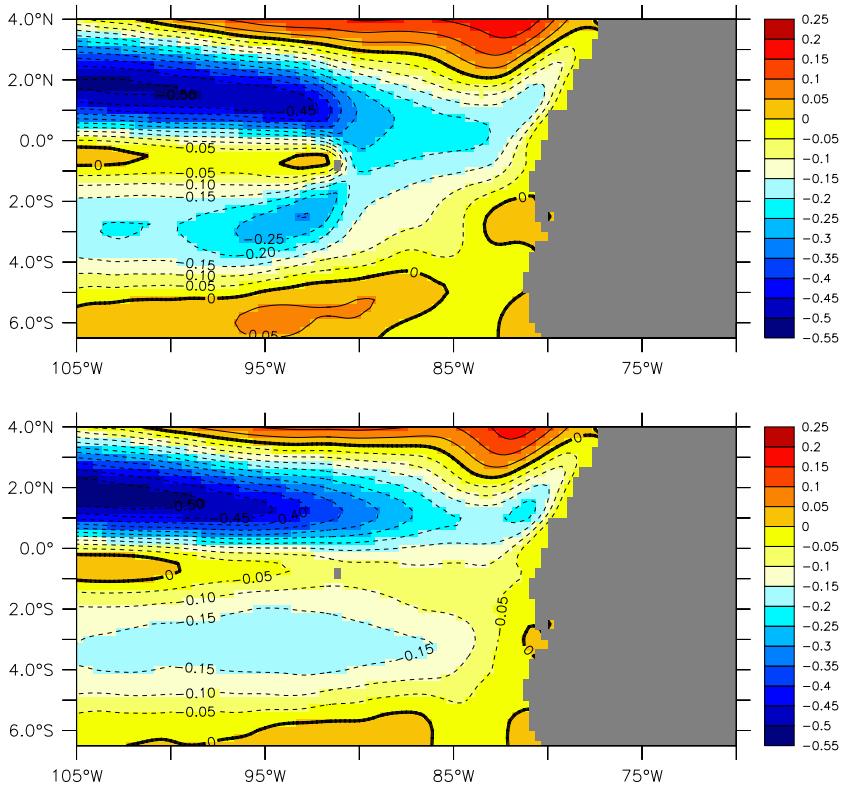

Figure 2. Upper panel: Near surface zonal currents $[\mathrm{m} / \mathrm{s}]$ averaged from Aug. till Dec. for the G-simulation. Lower panel: same for NG. Data are smoothed with a 5-grid point operator to enhance visibility. given by the model. This effect is characterized by cooling of about $1.5-2 \mathrm{~K}$ to the west of the islands, while east of the islands and in particular in the upwelling region near the coast of South America, Galápagos tend to warm the SST by about $0.6 \mathrm{~K}$. Note that the effect is strongest in boreal winter, but also visible in the other seasons. This relatively strong temperature sensitivity can be attributed to the effect of Galápagos on the oceanic flow, which is discussed next.

[6] Figure 2 shows the near surface zonal currents in the standard experiment (upper panel) and in NG (lower panel). In $\mathrm{G}$, the westward SEC bifurcates near Galápagos into a northern and a southern branch (while the northern branch is much stronger than the southern side). The difference between experiment $\mathrm{G}$ and NG (not shown) exhibits the typical large-scale wake pattern of the Galápagos Islands with influences on the near surface circulation in the eastern tropical Pacific. The associated flow anomalies attain values of up to $0.17 \mathrm{~m} / \mathrm{s}$, providing a strong distortion for the timemean flow of the SEC. Another, non-local effect of the Galápagos Islands arises from the acceleration of the southern branch of the SEC west of the islands, inducing large-scale flow anomalies of $5-10 \mathrm{~cm} / \mathrm{s}$ (not shown).

[7] Figure 3 (upper panel) shows the zonal currents in $80 \mathrm{~m}$ depth in $\mathrm{G}$. The most prominent flow feature is the eastward EUC with current speeds of $1 \mathrm{~m} / \mathrm{s}$ at maximum. The EUC is almost brought to rest by the Islands with the effect that only a small portion of the flow lingers around the Islands and reaches the continental shelf of South America. This lingering of the EUC is, however, seasonally dependent in the model: In boreal winter, the EUC is strongest such that in this season, the small appendix of the EUC reaches the continental shelf, while in other seasons it does not.
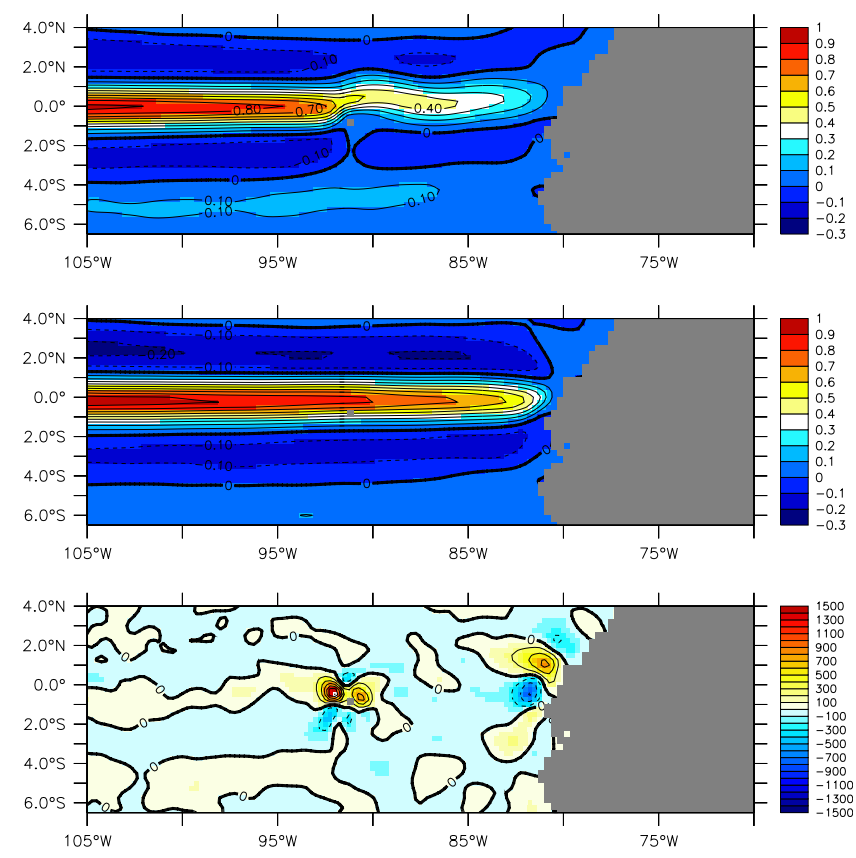

Figure 3. Upper panel: Zonal currents $[\mathrm{m} / \mathrm{s}]$ in $80 \mathrm{~m}$ depth averaged from Aug. till Dec. for the G-simulation. Middle panel: same for NG. Lower panel: Difference in vertical velocity in $[\mathrm{m} / \mathrm{y}]$ in $80 \mathrm{~m}$ depth (positive upward) and in Aug. till Dec. 
[8] In experiment NG (Figure 3, lower panel) the EUC reaches the coast of South America, thereby confirming the EUC wake hypothesis. In addition, the Galápagos Islands lead to a northward displacement of the EUC, generating flow anomalies of about $30 \mathrm{~cm} / \mathrm{s}$ in the entire basin (not shown). This effect is even stronger than the non-local wake effect on the SEC. The lower panel of Figure 3 shows the changes in upwelling induced by the presence of the Galápagos Islands. There is enhanced upwelling west of the Islands, leading to the reduction of SST in this region and reduced upwelling near the coast of South America, leading to a surface ocean warming, as seen in Figure 1.

\section{Influence on Tropical Instability Waves}

[9] Figure 4 shows the near surface Eddy Kinetic Energy (EKE) in experiment G. EKE is calculated from monthly mean velocity variances to exclude the seasonal cycle. There is a patch of high EKE with maximum amplitude of $800 \mathrm{~cm}^{2} / \mathrm{s}^{2}$ between the equator and about $5^{\circ} \mathrm{N}$ and west of the Galápagos Islands. This maximum is related to the activity of tropical instability waves (TIW, e.g., Legeckis [1977]).

[10] The effect of the Islands, expressed in terms of the EKE difference in G-NG, shows a large scale pattern of reduced and enhanced levels of EKE in the center of the high energy region with amplitudes of $200 \mathrm{~cm}^{2} / \mathrm{s}^{2}$. In the vicinity of the Galápagos Islands and thereof, we observe a reduction of EKE, whereas strongly enhanced EKE is attained west of the Islands at about $100^{\circ} \mathrm{W}$. Further to the west, from $110^{\circ} \mathrm{W}$ to about $130^{\circ} \mathrm{W}$ EKE is strongly reduced. This structure is continued by a region of enhanced EKE (to about $150^{\circ} \mathrm{W}$ ) and reduced EKE (west of $150^{\circ} \mathrm{W}$ ). Thus, we see a basin-scale standing wave like pattern of TIW activity as a result of the Islands wake effect.

[11] Since the eddy activity related to the TIW induces a significant equatorward heat transport, we expect an additional effect on SST by changes in TIW activity related to the Galápagos Islands, contributing to the changes in SST generated by the direct effect of the changes in the mean flow (SEC and EUC) and the associated upwelling. However, it is not the goal of our paper to quantify the relative magnitude of these effects. Figure 4 (lower panel) shows the difference (G-NG) in the basin-wide near surface temperatures. It is indeed evident, that the eddy activity pattern also matches up with the SST anomaly structure.

[12] The source region of the EKE associated with the TIW is obviously located in the vicinity of the Galápagos Islands, as seen in Figure 4 (upper panel). West of the Galápagos, the effect of the Islands is given by cooling of equatorial upper layer temperatures (by the blocked EUC and related upwelling), i.e., an enhanced meridional temperature gradient and thus enhanced vertical shear of the zonal velocity due to the thermal wind equation. In addition the wake effect generates also enhanced horizontal shear.

[13] This enhanced vertical and horizontal current shear give rise to enhanced production of EKE by transfer terms associated with baroclinic and barotropic instability (as $\overline{u^{\prime} v^{\prime}} \partial_{\mathrm{y}} \bar{u}$, respectively, where we use standard notation as in, for example, the work of Beckmann et al. [1994]. This leads to enhanced levels of EKE in this region, as documented in Figure 4 (middle panel). Closer inspection of the
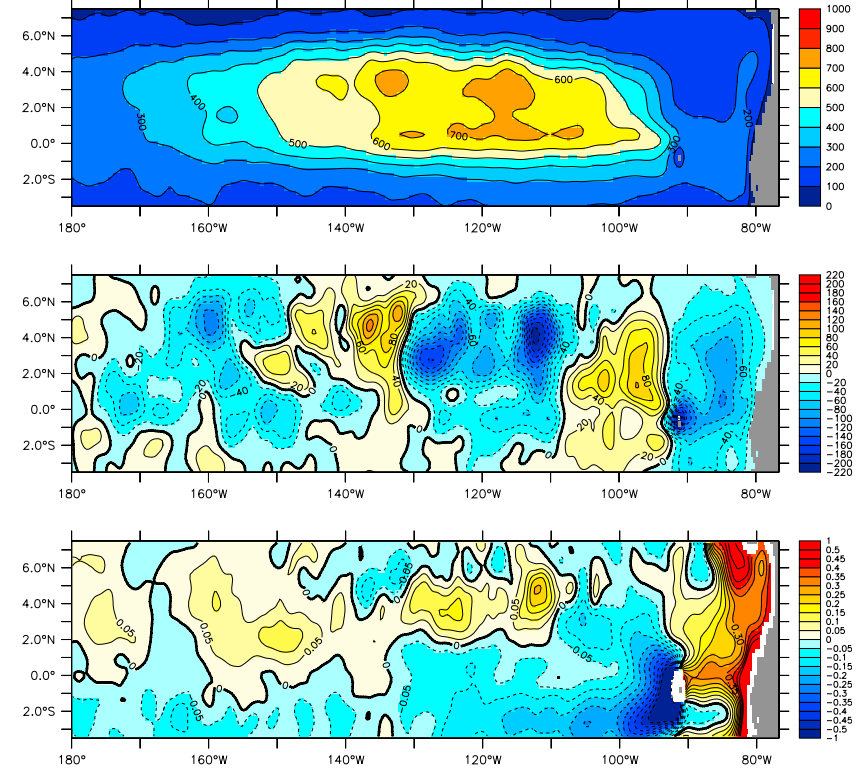

Figure 4. Near surface EKE in $\mathrm{cm}^{2} / \mathrm{s}^{2}$ averaged from Aug. till Dec. in experiment $G$ (upper panel) and difference (G-NG) (middle panel). Lower panel: Difference (G-NG) in near surface $(0-40 \mathrm{~m}$ average $)$ temperature in $K$. EKE and temperature data are smoothed with a 5-grid point operator to enhance visibility.

transfer terms reveals that changes in production terms of EKE due to the effect of Galápagos are mostly associated with barotropic instability (not shown).

[14] We may assume that in the vicinity of the Islands, changes in TIW are not feeding back on the mean flow, since here EKE is small compared to the region further west. Thus, the changes in TIW activity in the vicinity of the Galàpagos Islands can be explained in terms of changes in the local mean zonal flow. Further to the west, however, we are unable to determine cause and effect, i.e., changes in mean flow (and SST) are influencing and are being influenced by changes in EKE and EKE production terms. The large-scale wave pattern visible in the EKE change related to the Islands is affected and most likely generated by the complex interplay between mean flow and instabilities shall not be explained in detail here. However, the robustness of this remote wave train has to be explored with further model experiments (K. Richards, personal communication).

\section{Summary and Conclusions}

[15] This paper addresses the influence of the Galápagos Islands on the oceanic general circulation and the near surface thermal structure of the equatorial Pacific Ocean. The Galápagos Islands impose a topographic barrier both for the SEC and the EUC. In particular during the second half of the year, the effect of the islands is most pronounced. We identified the following effects:

[16] - The SEC bifurcates on the eastern side of the Islands, thereby creating a wake-like pattern with very weak easterly currents to the west of the Islands. The associated flow anomalies (G-NG) obtain values of about $15 \mathrm{~cm} / \mathrm{s}$ in the vicinity of the Islands with a zonal and meridional extent of $2000 \mathrm{~km}$ and $600 \mathrm{~km}$ respectively, and 
values of about $5-10 \mathrm{~cm} / \mathrm{s}$ along the entire tropical Pacific basin.

[17] - The Galápagos shield the EUC from the South American coast, except for a small lingering appendix of the EUC north of the equator, which may reach the coastline in boreal winter. The direct effect of this shielding are flow anomalies to the east of the Islands of up to $70 \mathrm{~cm} / \mathrm{s}$. Furthermore, a basin-wide southward displacement of the EUC can be observed as an effect of the Islands.

[18] - The EUC convergence on the eastern side of Galápagos leads to increased upwelling with possible implications on ecosystem [Jimenez, 1981] and local airsea coupling. In addition, we also find changes of upwelling of the same order of magnitude along the coast of South America.

[19] - These upwelling anomalies induce strong negative SST anomalies west of the Islands and of opposite sign along the Ecuadorian and Peruvian coast. In boreal winter season, these anomalies attain values of up to -2 and $0.6 \mathrm{~K}$, respectively. The area of the SST changes corresponds to the large area of the flow anomalies.

[20] - The bifurcation of the SEC and the upwelling EUC west of the Islands creates a zone of stronger meridional shear of the zonal current to the north and to the west of Galápagos which favors the generation of TIWs due to barotropic instability. The large-scale impact of the Islands is given by a stationary wave-like pattern, modulating the intensity of the TIW north of the equator by up to $25 \%$. Since the intensity of the TIWs induces a significant equatorward heat transport, the large scale pattern of TIW intensity generated by the Galápagos Islands has the potential to create temperature anomalies of the same order of magnitude as the changes in mean flow.

[21] Finally, we might speculate that in a coupled setup the effect of the Galápagos Islands is further amplified by positive tropical air-sea feedbacks (K. Richards, personal communication).

[22] Acknowledgments. A. Timmermann is supported by the Deutsche Forschungs Gemeinschaft through the Collaborative Research Project SFB460. We thank K. Richards,M. Jochum and an anonymous reviewers for constructive comments.

\section{References}

Arcos, F. (1981), A dense patch of Acartia levequei (Copepoda, Calanoida) in upwelled Equatorial Undercurrent water around the Galápagos Islands, in Costal Upwelling, Coastal Estuarine Stud., vol. 1, edited by F. A. Richards, pp. 427-432, AGU, Washington, D. C.

Barnier, B., L. Siefridt, and P. Marchesiello (1995), Thermal forcing for a global ocean circulation model using a three year climatology of ECMWF analysis, J. Mar. Syst., 6, 363-380.

Beckmann, A., C. W. Böning, C. Köberle, and J. Willebrand (1994), Effects of increased horizontal resolution in a simulation of the North Atlantic Ocean, J. Phys. Oceanogr., 24, 326-344.

Brentnall, S. J. (1999), The impact of the Galapagos Islands on the dynamics of the equatorial east Pacific, Ph.D. thesis, Univ. of Southampton, Southampton, England.

Dengg, J., C. W. Böning, U. Ernst, R. Redler, and A. Beckmann (1999), Effects of an improved model representation of overflow water on the subpolar North Atlantic, WOCE Newsl., 37, 10-15.

Gaspar, P., Y. Gregoris, and J.-M. Lefevre (1990), A simple eddy kinetic energy model for simulations of the oceanic vertical mixing: Tests at station PAPA and Long-Term Upper Ocean Study site, J. Geophys. Res., 95, 16,179-16,193.

Jimenez, R. (1981), Composition and distribution of phytoplankton in the upwelling system of the Galápagos Islands, in Costal Upwelling, Coastal Estuarine Stud., vol. 1, edited by F. A. Richards, pp. 327-338, AGU, Washington, D. C.

Kalnay, E., et al. (1996), The NCEP/NCAR 40-years reanalysis project, Bull. Am. Meteorol. Soc., 77, 437-471.

Legeckis, R. (1977), Long waves in the eastern equatorial Pacific Ocean: A view from a geostationary satellite, Science, 197(4309), 1179-1181.

Levitus, S., and T. P. Boyer (1994), World Ocean Atlas 1994, NOAA Atlas NESDIS 1-5, Natl. Oceanic and Atmos. Admin., Silver Spring, Md.

Longuet-Higgins, M. (1969), On the trapping of long period waves around islands, J. Fluid Mech., 37, 773-784.

Pacanowski, R. C. (1995), MOM 2 documentation: User's guide and reference manual, technical report, GFDL Ocean Group, Princeton, N. J.

Ripa, P., and S. P. Hayes (1981), Evidence for equatorial trapped waves at the Galapagos Islands, J. Geophys. Res., 86, 6509-6516.

Rowlands, P. B. (1982), The flow of equatorial Kelvin waves and the equatorial undercurrent around islands, J. Mar. Res., 40, 915-935.

Stevens, D. P. (1990), On open boundary conditions for three dimensional primitive equation ocean circulation models, Geophys. Astrophys. Fluid Dyn., 51, 103-133.

Stevenson, M. R., and B. A. Taft (1971), New evidence of the Equatorial Undercurrent east of the Galapagos Islands, J. Mar. Res., 29, 103-115.

White, W. B. (1971), A Rossby wake due to an island in an eastward current, J. Phys. Oceanogr., 1, 161-165.

White, W. B. (1973), An oceanic wake in the Equatorial Undercurrent downstream from the Galapagos Archipelago, J. Phys. Oceanogr., 3, $156-161$.

Yoon, J.-H. (1981), Effects of islands on equatorial waves, J. Geophys. Res., 86, 10,913-10,920.

Yoshida, K. (1959), A theory of the Cromwell current and equatorial upwelling, J. Oceanogr. Soc. Jpn., 15, 154-170.

C. Eden and A. Timmermann, Leibniz-Institut für Meereswissenschaften IFM-GEOMAR, Düsternbrooker Weg 20, 24105 Kiel, Germany. (ceden@ ifm.uni-kiel.de; atimmermann@ifm.uni-kiel.de) 